CARDIOVASCULAR MEDICINE

\title{
Metabolic syndrome and risk of coronary heart disease in a Pakistani cohort
}

\author{
A S Wierzbicki, S Nishtar, P J Lumb, M Lambert-Hammill, C N Turner, M A Crook, M S Marber, \\ J Gill
}

Heart 2005;91:1003-1007. doi: 10.1136/hrt.2003.033092

See end of article for authors' affiliations

\section{Correspondence to:}

Correspondence to:
Dr Anthony S Wierzbick Department of Chemical Pathology, St Thomas's Hospital, Lambeth Palace Road, London SE1 7EH, UK; anthony.wierzbicki@ kcl.ac.uk

Accepted

13 September 2004

\begin{abstract}
Objective: To assess the relation of the metabolic insulin resistance syndrome (M-IRS) with coronary heart disease (CHD) in Pakistani patients.

Subjects: 200 patients with angiographic disease $(C H D(+))$ matched with 200 patients with chest pain without occlusive disease (CHD(-)).

Design: Prospective case-control study.

Setting: Tertiary referral cardiology unit in Pakistan.

Results: M-IRS was present in $37 \%$ of $\mathrm{CHD}(+)$ versus $27 \%$ of $\mathrm{CHD}(-)$ patients by criteria for white patients or $47 \%$ versus $42 \%$, respectively, by Asian criteria ( $p<0.001$ ). After adjustment for other risk factors, $M$ IRS was not a significant predictor for CHD or angiographic disease. Age ( $p=0.03)$, smoking $(p<0.001)$, diabetes-years $(p=0.003)$, sialic acid $(p=0.01)$, and creatinine $(p=0.008)$ accounted for the excess risk of CHD. Similarly, age $(p=0.005)$, creatinine $(p<0.001)$, cigarette pack-years $(p=0.02)$, diabetes-years $(p=0.003)$, and sialic acid $(p=0.08)$ were predictors of greater angiographic disease. M-IRS differed between Pakistani and white patients, as waist circumference correlated weakly $(r=-0.03-0.08, p=0.45-0.52)$ with triglycerides, high density lipoprotein cholesterol, systolic blood pressure, or glucose. Sialic acid was the only inflammatory marker associated with M-IRS.

Conclusions: Despite strong associations between individual risk factors associated with M-IRS and a univariate association between M-IRS and CHD in native Pakistanis, the principal discriminant risk factors in this group are age, smoking, inflammation, diabetes-years, and impaired renal function. The poor sensitivity of M-IRS for CHD reflects the high underlying prevalence of M-IRS, thus reducing sensitivity, confounding by other urban lifestyle traits, or a lack of association of waist circumference with M-IRS risk factors. The definition of M-IRS may have to be revised to increase its power as a discriminant risk factor for CHD in Pakistani populations.
\end{abstract}

A therosclerotic disease is projected to become the leading cause of global morbidity and mortality by 2020 and is associated with the presence of the metabolic insulin resistance syndrome (M-IRS). ${ }^{1-3}$ Rates of coronary heart disease (CHD) are higher in Indian subcontinent Asians who have migrated and some studies suggest that rates of disease in the Indian subcontinent parallel those in the industrialised world. $^{4-6}$ This study examined the prevalence of M-IRS and its relation to occlusive CHD in a matched case-control study of patients with chest pain in Pakistan attending a tertiary referral hospital.

\section{METHODS}

The study cohort consisted of 400 patients recruited prospectively with ethical consent who underwent coronary angiography from 1998-2001 for presenting symptoms of chest pain. ${ }^{7}$ Two groups were selected based on the presence of significant CHD as defined by a $50 \%$ stenosis in one or more coronary arteries and an age and sex matched control group presenting with similar symptoms but with no angiographic evidence of disease.

After discharge from hospital, patients were recruited to the study and baseline anthropometric, dietary, and lifestyle variables were assessed. A detailed cardiovascular risk profile was obtained including smoking history, triplicate measurement of blood pressure by mercury sphygmomanometry, measurement of waist to hip ratio, and measurement of total body fat by an Omron BF300 impedance system (Omron, Milton Keynes, UK). Fasting blood samples were obtained for determination of biochemical risk factors including baseline renal function, liver function, glucose, insulin, lipids, apolipoproteins, $\mathrm{Lp}(\mathrm{a})$ lipoprotein, homocysteine, $\mathrm{C}$ reactive protein, and fibrinogen. Biochemical analytes were measured by automated methods on Cobas Mira and Fara 2 analysers, a Behring BN2 nephelometer, and the Corning ACS 180 immunoassay system. Homocysteine was measured by liquid chromatography and tandem mass spectrometry. Insulin resistance was calculated by the homeostasis model assessment $(\mathrm{HOMA})^{8}$ and glomerular filtration rate was approximated by calculation of creatinine clearance with the Cockcroft-Gault formula. ${ }^{9}$

The presence of M-IRS was identified by the NCEP-ATP III (National Cholesterol Education Program Adult Treatment Panel III) criteria of abdominal obesity: waist circumference $>102 \mathrm{~cm}$ in men and $>88 \mathrm{~cm}$ in women ${ }^{10}$ (adjusted criteria for Asians: waist $>90 \mathrm{~cm}$ in men and $>85 \mathrm{~cm}$ in women $)^{11}$; hypertriglyceridaemia $>1.70 \mathrm{mmol} / \mathrm{l}$; high density lipoprotein (HDL) cholesterol $<1.04 \mathrm{mmol} / \mathrm{l}$ in men and $<1.30$ $\mathrm{mmol} / \mathrm{l}$ in women; systolic blood pressure $>130 \mathrm{~mm} \mathrm{Hg}$; and fasting glucose $>6.1 \mathrm{mmol} / \mathrm{l}$. An additional analysis was

Abbreviations: $\mathrm{BMI}$, body mass index; $\mathrm{CHD}$, coronary heart disease; HDL, high density lipoprotein; HOMA, homeostasis model assessment; M-IRS, metabolic insulin resistance syndrome; NCEP-ATP III, National Cholesterol Education Program Adult Treatment Panel III; WHO, World Health Organization 
conducted with body mass index (BMI) $>28 \mathrm{~kg} / \mathrm{m}^{2}$ and $>25 \mathrm{~kg} / \mathrm{m}^{2}$ as alternative criteria for obesity and with stricter criteria from Chennai for abdominal obesity based on the incidence of diabetes (male $<85 \mathrm{~cm}$, female $<80 \mathrm{~cm}$ ). ${ }^{12}$

Statistical analysis was conducted by paired sample logistic regression analysis between $\mathrm{CHD}(+)$ and $\mathrm{CHD}(-)$ groups. Categorical data were quantified and compared by Fisher's exact test. The cohort was analysed by using baseline data or log transformed data depending on whether individual analyte distribution was Gaussian. Angiograms were quantified for the extent and severity of CHD by Gensini scoring by observers blinded to other clinical details. ${ }^{13}$ Multiple regression analysis was conducted with both backward and forward stepwise models to ascertain covariance and principal determinants of risk. Statistical analyses were conduced with GBStat 9.0 (Dynamic Microsystems, Silver Spring, Maryland, USA).

\section{RESULTS}

Table 1 shows patient demographic, lifestyle, and biochemical risk factors. Groups with and without CHD differed most significantly in age, percentage of body fat, waist to hip ratio, prevalence of diabetes, and HDL cholesterol and apolipoprotein A I concentrations. The distribution of angiographic disease was $52 \%$ with three vessel disease, 30\% with two vessel disease, and $18 \%$ with single vessel disease. Only $2 \%$ of patients in the $\mathrm{CHD}(-)$ group had any evidence of disease on angiography. Median (range) Gensini scores were 57 (8-224) and $0(0-3)$ in $\mathrm{CHD}(+)$ and $\mathrm{CHD}(-)$ groups, respectively $(\mathrm{p}<<0.001)$.

M-IRS was present in $31.5 \%$ of the group by US criteria (table 2 ) and $44 \%$ by Asian adjusted waist criteria (table 3 ). Substitution of BMI $>28 \mathrm{~kg} / \mathrm{m}^{2}$ for the waist $102 \mathrm{~cm}$ criterion in men resulted in the detection of $4 \%$ fewer cases. Similarly, substitution of BMI $>25 \mathrm{~kg} / \mathrm{m}^{2}$ for waist $90 \mathrm{~cm}$ in women reduced the number of cases by $2 \%$. Neither difference was significant and concordance with waist circumference criteria was $>90 \%$ for each measure. Given

Table 1 Anthropometric and lifestyle cardiovascular risk markers in a cohort study of a Pakistani population with $(\mathrm{CHD}(+))$ and without coronary heart disease $(\mathrm{CHD}(-))$

\begin{tabular}{|c|c|c|}
\hline Parameter & $\mathrm{CHD}(+)$ & $\mathrm{CHD}(-)$ \\
\hline Age (years) & $51.2(9.5)$ & $48.2(9.5)^{* * *}$ \\
\hline Urban & $72.5 \%$ & $67.0 \%$ \\
\hline Family history of IHD & $55.3 \%$ & $43.7 \% *$ \\
\hline Active smoking & $19.0 \%$ & $14.8 \% *$ \\
\hline $\mathrm{BMI}\left(\mathrm{kg} / \mathrm{m}^{2}\right)$ & $25.5(2.6)$ & $25.3(2.6)$ \\
\hline Waist $(\mathrm{cm}) \dagger$ & $90.8(6.7)$ & $88.5(8.0)^{*}$ \\
\hline Waist to hip ratio & $0.94(0.05)$ & $0.91(0.06)^{* * *}$ \\
\hline Diabetes & $9.3 \%$ & $4.7 \%$ \%** \\
\hline Blood pressure $(\mathrm{mm} \mathrm{Hg}) \dagger$ & $130(17) / 83(9)$ & $128(19) / 83(10)$ \\
\hline Creatinine $(\mu \mathrm{mol} / \mathrm{l})$ & $103(37)$ & $93(19)^{* *}$ \\
\hline Glucose (mmol/l)† & $6.84(2.05)$ & $6.06(1.16)^{* *}$ \\
\hline Insulin (pmol/l) & $23(2-449)$ & $2(2-424)^{*}$ \\
\hline HOMA insulin resistance & $1.40(0.07-33.0)$ & $0.12(0.07-41.0)^{*}$ \\
\hline Total cholesterol (mmol/l) & $4.28(0.79)$ & $4.25(0.74)$ \\
\hline Triglycerides $(\mathrm{mmol} / \mathrm{l}) \dagger$ & $1.24(0.37-3.62)$ & $1.18(0.08-3.98)$ \\
\hline $\mathrm{HDL}(\mathrm{mmol} / \mathrm{l}) \dagger$ & $0.73(0.14)$ & $0.86(0.17)^{* * *}$ \\
\hline $\mathrm{LDL}(\mathrm{mmol} / \mathrm{l})$ & $2.92(0.99)$ & $2.71(0.93)$ \\
\hline Apolipoprotein A I (g/l) & $1.09(0.12)$ & $1.19(0.15)^{* * *}$ \\
\hline Apolipoprotein B (g/l) & $0.93(0.23)$ & $0.91(0.27)$ \\
\hline Lp(a) lipoprotein (g/l) & $0.06(0.02-0.65)$ & $0.05(0.02-0.45)^{*}$ \\
\hline Fibrinogen (g/l) & $2.20(0.10-10.6)$ & $2.00(0.10-20.3)$ \\
\hline $\mathrm{C}$ reactive protein $(\mathrm{mg} / \mathrm{l})$ & $8.0(0.2-175)$ & $3.4(0.2-61)^{\star \star *}$ \\
\hline Homocysteine $(\mu \mathrm{mol} / \mathrm{l})$ & $18(6-92)$ & $19(7-69)$ \\
\hline
\end{tabular}

Data presented as mean (SD) or median (range). ${ }^{*} \mathrm{p}=0.02$ to $0.05 ;{ }^{* *} \mathrm{p}=0.01$ to $0.001 ;{ }^{* * *} \mathrm{p}<0.001$; †defining criteria. $\mathrm{BMI}$, body mass index; HDL, high density lipoprotein; HOMA, homeostasis model assessment; IHD, ischaemic heart disease; LDL, low density lipoprotein. the nature of the population the modified (reduced) waist circumference criteria were adopted for further analysis. Odds ratios for the presence of M-IRS were 2.05 for waist circumference $>102 \mathrm{~cm}$ for men and $>88 \mathrm{~cm}$ for women; 1.69 for waist circumference $>90 \mathrm{~cm}$ in men and $>85 \mathrm{~cm}$ in women; 2.08 for triglycerides $>1.69 \mathrm{mmol} / \mathrm{l} ; 1.09$ for HDL cholesterol $<1.04$ (1.30) mmol/l; 2.48 for systolic hypertension $(>130 \mathrm{~mm} \mathrm{Hg})$; and 2.24 for glucose $(>6.1 \mathrm{mmol} / \mathrm{l})$. The relation between waist circumference and triglycerides, HDL, systolic blood pressure, and glucose was negative but non-significant ( $r=-0.03$ to $0.08, \mathrm{p}=0.45$ to 0.52 ) in all cases. Similarly, BMI was related only to blood pressure in this study $(r=0.28, \mathrm{p}<0.001)$.

Table 2 and table 3 show the analysis of the cohort redefined into groups based on the presence or absence of $\mathrm{M}$ IRS. Clear differences $(\mathrm{p}<<0.001)$ existed between groups for the defining criteria of M-IRS: waist circumference, HDL cholesterol, triglycerides, blood pressure, and glucose. A clear correlation was found between presence of M-IRS and insulin resistance as defined by the HOMA index $(\mathrm{p}<0.001)$. More women than men had features of M-IRS (24\% v 10\% of the total cohort). The lipids profiles of patients with M-IRS showed evidence of hypertriglyceridaemia, relative depletion of cholesterol in HDL cholesterol (low HDL cholesterol to apolipoprotein A I ratio), and increased particle number (apolipoprotein B) despite lower relative cholesterol content (low density lipoprotein to apolipoprotein $\mathrm{B}$ ratio). Concentrations of sialic acid were increased in patients with M-IRS. Transaminase concentrations (aspartate aminotransferase) were higher in the group with M-IRS. No difference was noted in concentrations of $\mathrm{C}$ reactive protein, fibrinogen, homocysteine, or creatinine or in creatinine clearance rates between the two groups.

Analysis of the cohort by the revised Chennai criteria for waist circumference showed that $79 \%$ had M-IRS. CHD was found in $52 \%$ of the M-IRS $(+)$ group compared with $41 \%$ in the M-IRS $(-)$ group $(\mathrm{p}<0.001)$ with median Gensini scores of $11(0-224)$ compared with $0(0-140)(\mathrm{p}<<0.001)$ in the two groups, respectively. Consistent differences were found in the qualifying criteria for M-IRS between the groups (data not shown). However, no significant differences were found in sialic acid (79 (15) $v 80$ (14) mg/l, p $=0.43)$, C reactive protein, or fibrinogen between M-IRS (+) and M-IRS(-) groups according to these criteria. Calculated creatinine clearance (including BMI in the formula) was reduced in the group with M-IRS (87 (29) $v 91$ (41) $\mathrm{ml} / \mathrm{min}, \mathrm{p}=0.03$ ).

Logistic regression analysis coding M-IRS as a dichotomous variable and excluding the parameters that it comprises from the analysis showed that presence of significant angiographic disease was related with age $(\beta=0.026$, $\mathrm{p}=0.03)$, diabetes-years $(\beta=0.019, \mathrm{p}=0.003)$, smoking in pack-years $(\beta=0.016, p<0.001)$, sialic acid $(\beta=0.01$, $\mathrm{p}=0.01)$, and creatinine $(\beta=0.013, \mathrm{p}=0.008)$ but not with M-IRS. Gensini score of atherosclerotic burden $(r=0.41, \mathrm{p}<0.001)$ correlated with age $(\beta=0.67$, $\mathrm{p}=0.005)$, creatinine $(\beta=0.41, \mathrm{p}<0.001)$, diabetesyears $(\beta=0.08, p=0.003)$, cigarette pack-years $(\beta=0.02$, $\mathrm{p}=0.02)$, and sialic acid $(\beta=0.28, \mathrm{p}=0.08)$ but not with M-IRS. To correct for the insensitivity of a dichotomous classification of M-IRS, the analysis was repeated with the grade of M-IRS coded by the total number of parameters exceeding defined limits for the three definitions of M-IRS. Results obtained were similar to those obtained with the dichotomous definition of M-IRS. Exclusion of diabetes-years did not force inclusion of M-IRS into either model.

\section{DISCUSSION}

Rates of CHD in both Asian migrants to the industrialised world and in the Indian subcontinent are rapidly 
Table 2 Population characteristics and biochemical variables in 400 Pakistani patients with and without metabolic syndrome according to NCEP-ATP III criteria

\begin{tabular}{|c|c|c|}
\hline Parameter & $\begin{array}{l}\text { Metabolic syndrome } \\
(n=127)\end{array}$ & $\begin{array}{l}\text { No metabolic syndrome } \\
(n=273)\end{array}$ \\
\hline $\mathrm{CHD}(+)$ & $58 \% * * *$ & $46 \%$ \\
\hline Gensini score & $18(0-154)^{* * *}$ & $0(0-224)$ \\
\hline Age (years) & $51.8(9.7)^{\star * *}$ & $48.8(9.5)$ \\
\hline Men & $76 \% * * *$ & $88 \%$ \\
\hline Blood pressure $(\mathrm{mm} \mathrm{Hg}) \dagger$ & $142(18) / 88(9)^{* * *}$ & $123(15) / 80(9)$ \\
\hline BMI $\left(\mathrm{kg} / \mathrm{m}^{2}\right)$ & $26.6(3.7)^{* \star *}$ & $24.8(3.4)$ \\
\hline Waist $(\mathrm{cm}) \dagger$ & $93(10)^{* * *}$ & $89(9)$ \\
\hline Total cholesterol (mmol/l) & $4.25(1.06)$ & $4.27(1.09)$ \\
\hline Triglycerides $(\mathrm{mmol} / \mathrm{l}) \dagger$ & $1.70(0.61-3.62)^{* * *}$ & $1.09(0.08-3.98)$ \\
\hline $\mathrm{HDL}(\mathrm{mmol} / \mathrm{l}) \dagger$ & $0.74(0.19)^{\star * *}$ & $0.82(0.24)$ \\
\hline $\mathrm{LDL}(\mathrm{mmol} / \mathrm{l})$ & $2.70(0.98)$ & $2.88(0.96)$ \\
\hline Apolipoprotein A I (g/l) & $1.14(0.20)$ & $1.14(0.20)$ \\
\hline Apolipoprotein B (g/l) & $0.95(0.26)^{*}$ & $0.90(0.25)$ \\
\hline HDL:apolipoprotein A I & $0.65(0.14)^{* * *}$ & $0.72(0.15)$ \\
\hline LDL:apolipoprotein B & $2.83(0.74)^{\star * \star}$ & $3.19(0.63)$ \\
\hline AST (IU/I) & $24(9-109)$ & $22(7-171)$ \\
\hline Lp(a) lipoprotein (g/l) & $0.05(0.02-0.45)$ & $0.06(0.02-0.65)$ \\
\hline $\mathrm{C}$ reactive protein $(\mathrm{mg} / \mathrm{l})$ & $5(0.3-87)$ & $6(0.2-176)$ \\
\hline Fibrinogen $(\mathrm{g} / \mathrm{l})$ & $2.20(0.70-20.20)$ & $2.10(0.80-10.60)$ \\
\hline Sialic acid (mg/l) & $83(13)^{* * *}$ & $78(15)$ \\
\hline Glucose $(\mathrm{mmol} / \mathrm{l}) \dagger$ & $7.70(2.94)^{\star * *}$ & $5.85(1.71)$ \\
\hline Insulin (pmol/I) & $25(2-356)^{\star * *}$ & $2(2-449)$ \\
\hline HOMA insulin resistance & $8.3(0.4-164)^{* * *}$ & $0.62(0.4-211)$ \\
\hline Creatinine clearance $(\mathrm{ml} / \mathrm{min})$ & $91(27-257)$ & $82(15-276)$ \\
\hline Homocysteine $(\mu \mathrm{mol} / \mathrm{l})$ & 18 (7-92) & $18(6-56)$ \\
\hline
\end{tabular}

increasing. ${ }^{14-16}$ The higher incidence of diabetes, low HDL, hypertriglyceridaemia, increased BMI, insulin resistance, and hence the likely presence of M-IRS are consistent risk factors for CHD in migrant Indian Asians. ${ }^{17-19}$ However, few studies have assessed the utility of current definitions of M-IRS as CHD risk factors in native Indian Asian populations. ${ }^{10}$ Though the NCEP-ATP III criteria have been adjusted, as these are inappropriate for Indian Asians, the exact values to be substituted are controversial. Generally a waist circumference of $90 \mathrm{~cm}$ for men and $85 \mathrm{~cm}$ for women is used, ${ }^{11}$ but data from the Chennai study suggest that cut offs of $85 \mathrm{~cm}$ and $80 \mathrm{~cm}$ may be more appropriate. ${ }^{12}$ According to the adjusted criteria M-IRS is present in $44 \%$, which is similar to the prevalence of $41 \%$ seen in the urban Chennai study. ${ }^{11}$ When the analysis was conducted with the revised Chennai criteria based on risk of development of non-insulin

Table 3 Population characteristics and biochemical variables in 400 Pakistani patients with and without metabolic syndrome defined by NCEP-ATP III modified for waist circumference

\begin{tabular}{|c|c|c|}
\hline Parameter & $\begin{array}{l}\text { Metabolic syndrome } \\
(n=176)\end{array}$ & $\begin{array}{l}\text { No metabolic syndrome } \\
(n=224)\end{array}$ \\
\hline $\mathrm{CHD}(+)$ & $53 \%$ *** & $48 \%$ \\
\hline Gensini score & $11(0-154)^{* * *}$ & $0(0-224)$ \\
\hline Age (years) & $51.4(9.5)^{\star \star *}$ & $48.5(9.5)$ \\
\hline Men & $76 \% * * *$ & $90 \%$ \\
\hline Blood pressure $(\mathrm{mm} \mathrm{Hg}) \dagger$ & $139(18) / 87(9)^{* * *}$ & $120(13) / 80$ (9) \\
\hline BMI $\left(\mathrm{kg} / \mathrm{m}^{2}\right)$ & $26.5(3.7)^{* * *}$ & $24.5(3.4)$ \\
\hline Waist $(\mathrm{cm}) \dagger$ & $90(10)^{* \star *}$ & $87(9)$ \\
\hline Total cholesterol (mmol/l) & $4.29(1.13)$ & $4.25(1.04)$ \\
\hline Triglycerides $(\mathrm{mmol} / \mathrm{l}) \dagger$ & $1.48(0.34-3.98)^{\star * *}$ & $1.07(0.08-3.34)$ \\
\hline $\mathrm{HDL}(\mathrm{mmol} / \mathrm{l}) \dagger$ & $0.75(0.22)^{\star * *}$ & $0.83(0.23)$ \\
\hline $\mathrm{LDL}(\mathrm{mmol} / \mathrm{l})$ & $2.77(1.06)$ & $2.86(0.88)$ \\
\hline Apolipoprotein A I (g/l) & $1.14(0.20)$ & $1.13(0.21)$ \\
\hline Apolipoprotein B (g/l) & $0.96(0.27)^{*}$ & $0.89(0.24)$ \\
\hline HDL:apolipoprotein A I & $0.66(0.15)^{\star \star \star}$ & $0.73(0.15)$ \\
\hline LDL:apolipoprotein B & $2.88(0.74)^{\star \star *}$ & $3.23(0.60)$ \\
\hline AST (IU/I) & $24(9-109)^{*}$ & $22(7-171)$ \\
\hline Lp(a) lipoprotein (g/l) & $0.05(0.02-0.45)$ & $0.06(0.02-0.65)$ \\
\hline $\mathrm{C}$ reactive protein $(\mathrm{mg} / \mathrm{l})$ & $5(0.3-175)$ & $6(0.2-83)$ \\
\hline Fibrinogen (g/l) & $2.20(0.10-20.20)$ & $2.00(0.10-10.60)$ \\
\hline Sialic acid (mg/l) & $82(13)^{\star \star \star}$ & $77(15)$ \\
\hline Glucose $(\mathrm{mmol} / \mathrm{l}) \dagger$ & $7.3(2.9)^{\star * *}$ & $5.7(1.5)$ \\
\hline Insulin (pmol/l) & $45(2-449)^{* * *}$ & $2(2-424)$ \\
\hline HOMA insulin resistance & $6.8(0.4-164)^{\star * *}$ & $0.6(0.4-211)$ \\
\hline Creatinine clearance $(\mathrm{ml} / \mathrm{min})$ & $91(26-257)$ & $81(15-276)$ \\
\hline Homocysteine $(\mu \mathrm{mol} / \mathrm{l})$ & $18(6-92)$ & $19(7-56)$ \\
\hline
\end{tabular}

Data presented as mean (SD) or median (range).

${ }^{*} \mathrm{p}=0.02-0.05 ;{ }^{* *} \mathrm{p}=0.01-0.001 ;{ }^{* * *} \mathrm{p}<0.001$; tdefining criteria. 
dependent diabetes ${ }^{12}$ - that is, with even more reduced waist circumference criteria-M-IRS was present in $77 \%$ of the total cohort and $52 \%$ were $\mathrm{CHD}(+)$ in the M-IRS(+) group compared with $41 \% \mathrm{CHD}(+)$ in the M-IRS $(-)$ group $(p<0.001)$. In all these analyses differences in lipids and HOMA insulin resistance correlated well with the presence of M-IRS. In one analysis the presence of increased transaminases correlated with presence of M-IRS indicating that the definition may be used to identify hepatic steatosis.

Previous analysis of the cardiovascular risk profile in this population had shown that the presence of angiographic disease correlated with the presence of M-IRS (crudely defined as increased waist to hip ratio, low HDL, high triglycerides, and hyperglycaemia or HOMA insulin resistance) allied with nephropathy and inflammation. ${ }^{7}$ However, the previous study did not assess the relation between angiographic disease and M-IRS as formally defined by white NCEP or modified NCEP criteria. It was not possible to assess M-IRS defined by the World Health Organization (WHO) criteria, ${ }^{20}$ as urine albumin was not measured in this study. This analysis shows that there is an increased prevalence of CHD in patients with M-IRS as defined by the native white and modified Asian criteria in univariate analysis. However, after correction for other risk factors by logistic regression analysis for the presence of angiographic disease or in multiple regression analysis with the Gensini score as an index of atherosclerotic burden, the presence of the M-IRS was not significantly associated with disease. The prime determinants associated with CHD events in this Pakistani population were age, smoking, inflammatory markers, creatinine or calculated glomerular filtration rate, and presence of diabetes. The Cockcroft-Gault formula for glomerular filtration rate includes BMI indicating that the CHD risk associated with renal dysfunction in this population is not completely subsumed within the definition of M-IRS by any of the waist circumference or analogous BMI criteria used. Similarly presence of diabetes was independently associated with CHD or angiographic disease and was not subsumed within the presence of M-IRS as a risk factor.

In contrast to studies in white patients, ${ }^{21}{ }^{22}$ no clear association of CHD with M-IRS above other risk factors is found in native Pakistani patients. This may reflect the patients selected for this study, as they were derived from an urban cohort presenting with chest pain to a tertiary centre and consequently were more likely to have higher incomes, to have greater rates of obesity, diabetes, and smoking, and to take less exercise than rural populations. Alternatively, the high population prevalence of M-IRS in Pakistanis $137 \%$ in $\mathrm{CHD}(+)$ compared with $27 \%$ in $\mathrm{CHD}(-)$ by NCEP-ATP III criteria or $47 \%$ compared with $42 \%$ by modified criteria) may reduce the sensitivity of using M-IRS as a discriminating factor to identify high risk patients with CHD. This effect is seen in this study, as prevalences of M-IRS rise and odds ratios for association of uncorrected M-IRS with CHD or angiographic disease fall as waist circumference criteria are reduced. Similar specificity-sensitivity trade offs affect other risk assessment systems ${ }^{23}$ and a detailed receiver operating characteristic curve analysis would be required to determine the optimal cut off criteria in this patient group. However, more fundamentally the effect may reflect a flaw in the definition of M-IRS in this group, as lipids, blood pressure, or glucose did not correlate with waist circumference within MIRS in this population. The lack of correlation of lipids with waist circumference has previously been noted in Sikh migrants to the $\mathrm{UK}^{18}$; however, a relation was found between BMI and blood pressure suggesting that the optimal definition of M-IRS for Asians may differ from that for white patients. Similarly, validation studies of M-IRS criteria in white patients have shown that the NCEP criteria have a high specificity and WHO high sensitivity for prediction of diabetes indicating that these definitions may identify different aspects of the hypertriglyceridaemic waist syndrome. ${ }^{24}$ Studies in native Indian Asian populations suggest that similar limitations may affect these populations but have not clarified the optimal definition of M-IRS in this ethnic group. ${ }^{11}{ }^{12}$

The association of risk of CHD with sialic acid in this population parallels that seen in patients with non-insulin dependent diabetes and extends the data for this risk factor to patients with M-IRS. ${ }^{25}{ }^{26}$ No association was found with fibrinogen or $\mathrm{C}$ reactive protein concentrations ${ }^{19}{ }^{21}$ and M-IRS but this may reflect a higher burden of infectious disease in this population obscuring an underlying relation, as $45 \%$ of M-IRS(+) patients and $47 \%$ of M-IRS(-) patients had concentrations of $\mathrm{C}$ reactive protein $>6 \mathrm{mg} / \mathrm{l}$.

This study shows that, despite strong associations of individual risk factors associated with M-IRS and a univariate association with $\mathrm{CHD}$ in native Pakistanis, the principal discriminant risk factors in this group are age, smoking, inflammation, diabetes, and impaired renal function. M-IRS seems to have a poor sensitivity as a discriminatory factor to identify high risk patients for CHD. This may reflect the high underlying prevalence of M-IRS reducing sensitivity, confounding by urban lifestyle traits often associated with M-IRS, or lack of a clear association of waist circumference with other risk factors for M-IRS in this population. The definition of M-IRS may have to be revised to increase its power as a discriminant risk factor for CHD in Indian Asian populations.

\section{ACKNOWLEDGEMENTS}

The authors thank Dr Rehana Ahmad, Miss Rehana Ahmad, Dr Adeela Amir, and the staff of the Pakistan Institute of Medical Sciences for their help with patient recruitment. Funding support form the Pakistan Medical Research Council is gratefully acknowledged.

\section{Authors' affiliations}

A S Wierzbicki, P J Lumb, M Lambert-Hammill, M A Crook, Department of Chemical Pathology, St Thomas's Hospital, London, UK

S Nishtar, Heartfile, 1-Park Road, Chak Shazad, Islamabad, Pakistan

C N Turner, Department of Paediatrics, St Thomas's Hospital

M S Marber, J Gill, Department of Cardiology, St Thomas's Hospital

\section{REFERENCES}

1 Yusuf S, Reddy S, Ounpuu S, et al. Global burden of cardiovascular diseases. Part I: general considerations, the epidemiologic transition, risk factors, and impact of urbanization. Circulation 2001;104:2746-53.

2 Ounpuu S, Anand S, Yusuf S. The impending global epidemic of cardiovascular diseases. Eur Heart J 2000;21:880-3.

3 Yusuf S, Ounpuu S. Tackling the growing epidemic of cardiovascular disease in South Asia. J Am Coll Cardiol 2001;38:688-9.

4 Yusuf S, Reddy S, Ounpuu S, et al. Global burden of cardiovascular diseases. Part II: variations in cardiovascular disease by specific ethnic groups and geographic regions and prevention strategies. Circulation 2001; 104:2855-64.

5 Enas EA, Garg A, Davidson MA, et al. Coronary heart disease and its risk factors in first-generation immigrant Asian Indians to the United States of America. Indian Heart J 1996:48:343-53.

6 Nishtar S. Prevention of coronary heart disease in south Asia. Lancet 2002;360:1015-8.

7 Nishtar S, Wierzbicki AS, Lumb PJ, et al. Waist-hip ratio and low HDL predict the risk of coronary artery disease in Pakistanis. Curr Med Res Opin 2004;20:55-62.

8 Matthews DR, Hosker JP, Rudenski AS, et al. Homeostasis model assessment: insulin resistance and beta-cell function from fasting plasma glucose and insulin concentrations in man. Diabetologia 1985;28:412-9.

9 Cockcroft DW, Gault MH. Prediction of creatinine clearance from serum creatinine. Nephron 1976;16:31-41.

10 NCEP. Executive summary of the third report of the National Cholesterol Education Program (NCEP) expert panel on detection, evaluation, and treatment of high blood cholesterol in adults (adult treatment panel III). JAMA 2001;285:2486-97. 
11 Ramachandran A, Snehalatha C, Satyavani K, et al. Metabolic syndrome in urban Asian Indian adults: a population study using modified ATP III criteria. Diabetes Res Clin Pract 2003;60:199-204.

12 Snehalatha C, Viswanathan V, Ramachandran A. Cutoff values for normal anthropometric variables in Asian Indian adults. Diabetes Care 2003;26:1380-4.

13 Gensini GG. A more meaningful scoring system for determining the severity of coronary heart disease. Am J Cardiol 1983;51:606.

14 Bhatnagar D, Anand IS, Durrington PN, et al. Coronary risk factors in people from the Indian subcontinent living in west London and their siblings in India. Lancet 1995;345:405-9.

15 Ramachandran A, Sathyamurthy I, Snehalatha C, et al. Risk variables for coronary artery disease in Asian Indians. Am J Cardiol 2001;87:267-71.

16 Misra A, Reddy RB, Reddy KS, et al. Clustering of impaired glucose tolerance, hyperinsulinemia and dyslipidemia in young north Indian patients with coronary heart disease: a preliminary case-control study. Indian Heart J 1999;51:275-80.

17 McKeigue PM, Marmot MG, Adelstein AM, et al. Diet and risk factors for coronary heart disease in Asians in northwest London. Lancet, 1985;ii, 1086-90.

18 Gama R, Elfatih AB, Anderson NR. Ethnic differences in total and HDL cholesterol concentrations: caucasians compared with predominantly Punjabi Sikh Indo-Asians. Ann Clin Biochem 2002;39:609-11.

19 Chambers JC, Eda S, Bassett $\mathrm{P}$, et al. C-reactive protein, insulin resistance, central obesity, and coronary heart disease risk in Indian Asians from the
United Kingdom compared with European whites. Circulation $2001 ; 104: 145-50$

20 Alberti KG, Zimmet PZ. Definition, diagnosis and classification of diabetes mellitus and its complications. Part 1: diagnosis and classification of diabetes mellitus provisional report of a WHO consultation. Diabet Med 1998; 15:539-53.

21 Sattar N, Gaw A, Scherbakova O, et al. Metabolic syndrome with and without C-reactive protein as a predictor of coronary heart disease and diabetes in the west of Scotland coronary prevention study. Circulation 2003:108:414-9.

22 Lakka HM, Laaksonen DE, Lakka TA, et al. The metabolic syndrome and total and cardiovascular disease mortality in middle-aged men. JAMA 2002;288:2709-16.

23 Reynolds TM, Twomey PJ, Wierzbicki AS. Concordance evaluation of coronary risk scores: implications for cardiovascular risk screening. Curr Med Res Opin 2004;20:811-8.

24 Laaksonen DE, Lakka HM, Niskanen LK, et al. Metabolic syndrome and development of diabetes mellitus: application and validation of recently suggested definitions of the metabolic syndrome in a prospective cohort study. Am J Epidemiol 2002;156:1070-7.

25 Crook M, Kerai $P$, Andrews $V$, et al. Serum sialic acid, a reputed cardiovascular risk factor, is elevated in South Asian men compared to European men. Ann Clin Biochem 1998;35:242-4.

26 Pickup JC, Mattock MB, Crook MA, et al. Serum sialic acid concentration and coronary heart disease in NIDDM. Diabetes Care 1995; 18:1100-3.

\section{IMAGES IN CARDIOLOGY}

\section{Unusual coronary sinus anatomy: the vein of Marshall}

doi: 10.1136/hrt.2004.055202

A 76 year old man with dilated ischaemic cardiomyopathy, severe left ventricular dysfunction, and left bundle branch block was admitted for implantation of a biventricular internal cardioverter-defibrillator. The procedure was performed via the left subclavian approach and pacing leads were implanted into the right atrium and right ventricle. Coronary sinus (CS) angiography was then carried out to identify a suitable target vein for the left ventricular lead. Initial angiography (left anterior oblique (LAO) 10 projection) suggested that the CS was occluded with a small venous tributary (panel A, double arrow) leading up to the left subclavian vein. Further contrast injections into the CS, however, demonstrated that the CS was widely patent (panel B) with an excellent posterolateral (PL) vein arising from the main CS body. The initial stump was identified as the vein of Marshall (VM), the remnants of the left cardinal vein that may give rise to a persistent left superior vena cava. While

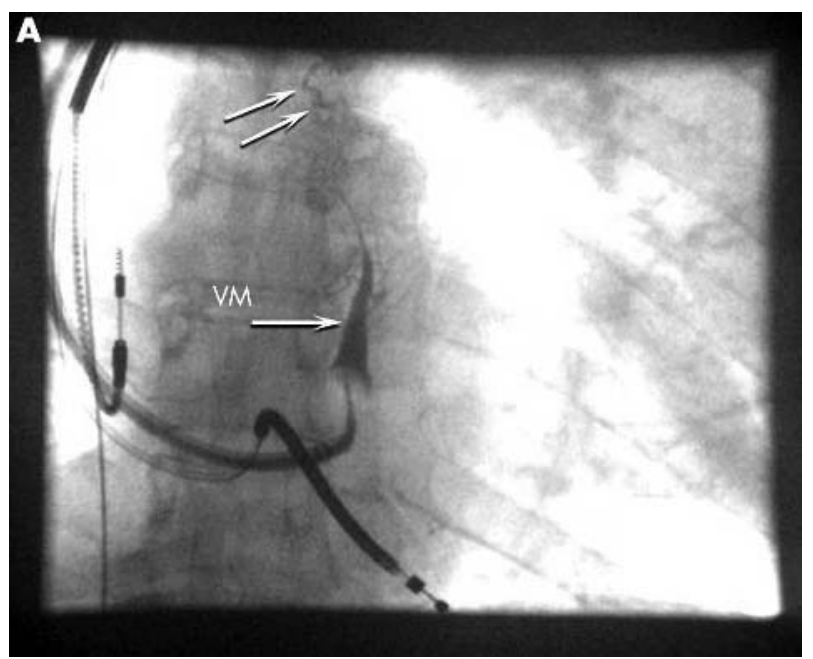

these are well documented, a patent vein of Marshall is extremely unusual. On this occasion the guide catheter sat preferentially within this channel and gave the appearance of a CS which was unfavourable for lead placement. It was only after further manipulation of the guide catheter and contrast injections that the true anatomy of the CS was revealed.

We feel this is an important anatomical variant to be demonstrated, as an increasing number of CS angiograms are performed because of biventricular device implants. This may help the unsuspecting cardiologist who may encounter this anomaly and initially conclude that the CS is unfavourable for pacing.

D J Fox

A Zaidi A P Fitzpatrick david.j.fox@talk21.com

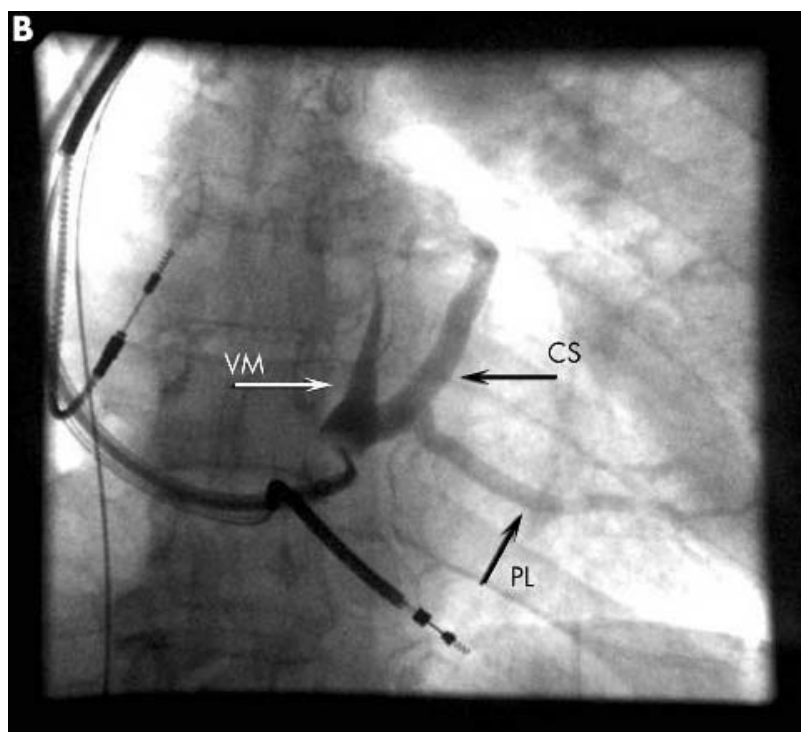

